\title{
Informal Payments and Performance in the Health Care Sector: Possible Relationships in a Sub-National Perspective
}

\author{
Elisabetta Reginato ${ }^{1}$, Isabella Fadda ${ }^{1}$, Paola Paglietti ${ }^{1}$ \& Aldo Pavan ${ }^{1}$ \\ ${ }^{1}$ Department of Economics and Business Studies, University of Cagliari, Italy \\ Correspondence: Isabella Fadda, Department of Economics and Business Studies, University of Cagliari, Viale S. \\ Ignazio 17, I-09123, Italy. E-mail: isafadda@unica.it
}

Received: January 14, 2020

Accepted: February 5, 2020

Online Published: February 28, 2020

doi:10.5539/ijbm.v15n3p126

URL: https://doi.org/10.5539/ijbm.v15n3p126

\begin{abstract}
The paper explores the relationship between corruption and performance dimensions of the Italian regional health care systems (RHSs). In Europe, Italy shows the widest sub-national in performance and corruption levels. The research focuses on petty corruption in health care. So-called informal payments are the most common form and were measured using data from the European Quality of Government Index Survey. The performance of Italian RHSs was assessed using key indicators divided into three analytical dimensions: health status; access to care; and quality of care. OECD Health Data was used as source data for health status and access to care. As a proxy for quality of care, the study used avoidable mortality, with data drawn from the Italian National Institute of Statistics (ISTAT). The study formulated a research hypothesises that petty corruption has a negative influence on RHS performance. The findings showed considerable regional differences. The results did not confirm the research hypotheses. However, informal payments did show an adverse effect on renunciations to specialist medical examinations due to costs.
\end{abstract}

Keywords: corruption, health care, informal payments, performance

\section{Introduction}

The health care sector, more than other areas in Western society, is prone to corruption. Factors include uncertainty surrounding the demand for health care services; large numbers of dispersed actors; and asymmetric information available to them (Savedoff \& Hussmann, 2006; Holmberg \& Rothstein, 2011; Vian, 2015; Koheler, 2019). This sector is particularly vulnerable to abuse because so much public money is allocated to health spending in many countries, and private actors are entrusted with important public roles. When private actors behave dishonestly, they are not formally abusing 'public office for private gain,' but they are abusing the public's trust (Savedoff \& Hussmann, 2006).

According to Transparency International, corruption is defined as 'the abuse of entrusted power for private gain' (2009, p. 14). It can take many different forms, ranging from petty to grand corruption. The former relates to lower-level bureaucrats who control access to public services. The latter is practised by high-level leaders and senior public servants. Grand corruption involves huge amounts of money or political influence, and it is usually associated with procurement and investment decisions (Hussmann, 2011; Mungiu-Pippidi, 2016).

Numerous studies show the adverse impact of corruption on standard measures of population health, such as child and maternal mortality rates and life expectancy from birth (Azfar, 2005; Gupta, Davoodi \& Tiongson, 2001; Hanf, Van-Melle, Fraisse, Roger, Carme \& Nacher, 2011; Hanf, Nacher, Guihenneuc, Tubert-Bitter \& Chavance, 2013; Lewis 2006; Muldoon et al. 2011; Rose, 2006). Conversely, there is little research about the consequences of corruption on health care system performance in terms of equity of access and service quality (Klomp \& Hann, 2008). This is especially true at the sub-national level. A sub-national analysis offers unique measurement challenges, particularly when health service performance and corruption present vast regional differences (Charron, Dijkstra \& Lapuente, 2015; Charron, Dijkstra \& Lapuente, 2014; Charron, 2013). Overlooking such substantial differences within countries may lead to distorted inferences and poorly designed policy prescriptions.

The present study contributes to fill the literature gap by investigating the possible relationship between corruption and health care sector performance in a sub-national perspective. The research focuses on petty 
corruption in health care. The most common form involves so-called informal payments. The study uses the Italian National Health Service (NHS), composed of 20 regional health care systems (RHSs). The Italian case is relevant because regional performance shows considerable differences (Fattore, 1999; Del Vecchio, Fenech \& Prenestini, 2015; Reginato, 2016; Toth, 2014). Moreover, in Europe, Italy offers the widest regional variation in corruption data (Charron, 2013; Charron, Dijkstra \& Lapuente, 2014; Charron, Dijkstra \& Lapuente, 2015).The literature emphasises that it's problematic to describe corruption using a national aggregate measure (Seligson, 2006) and recommends a sub-national level analysis.

The paper is structured as follows: Section 2 provides the literature background on corruption in the health care sector; Section 3 describes the corruption phenomenon in the Italian NHS; Section 4 illustrates the research question and method; Section 5 presents the data analysis; Section 6 provides the discussion of results and offers conclusions and implications for future research in this field.

\section{Background}

Corruption is a systemic feature of public and private health systems because of organisational factors. These factors include uncertainty, a large number of dispersed actors and asymmetric information (Savedoff \& Hussmann, 2006; Vian 2008; Vian, 2015).

There is uncertainty surrounding the demand for health care services. This uncertainty refers to an inability to know how many people will become ill, what kind of diseases they will contract, and how effective the care provided will be. When people fall ill, they cannot judge whether the prescribed treatment is appropriate or search for the best service quality, if they ignore the precise nature of their needs. This uncertainty in selecting monitoring, measuring and delivery of health care services makes it difficult to detect and assign responsibility for abuses (Savedoff \& Hussmann, 2006).

Health systems are prone to corruption because of the many actors involved. They can be classified in five categories: regulators, payers, providers, suppliers and patients. Roles and responsibilities within health systems are split between them in ways that might increase the number of opportunities for corruption. The relationships among drug and medical equipment suppliers, health care providers and policy-makers are often opaque. These actors may take advantage of their positions for financial gain, to increase their power and prestige, or to expand their market share. Meanwhile, patients often pay bribes to get privileged access to health services (Savedoff \& Hussmann, 2006).

The high degree of asymmetric information among different actors is another dimension that makes the health sector vulnerable to abuse (Holmberg \& Rothstein, 2011). For example, pharmaceutical companies know more about their products than physicians who prescribe them. On the one hand, the market power of these drug companies creates conflicts of interest between business objectives and the duty to prescribe the most appropriate care. On the other hand, it creates and favours a culture of bribery (Lantham, 2001; Kassirer, 2006). Providers are better informed than patients in terms of treatments and medications. They are in a unique position of telling users what services they need. In particular, the patient-provider relationship is characterised by forms of petty corruption. These include: inappropriate ordering of tests and procedures to increase financial gain; use of government resources for private practice; and bribes extorted at the service-delivery level, which are generally known as informal payments or under-the-table payments.

The present paper focuses on these service-delivery abuses that represent one of the most common forms of petty corruption in health care (European Commission, 2013). They are a common feature of health systems in which public sector finances and directly provides for health services. They are also characterised by an excess supply of capital and human resources, low salaries, lack of accountability and government oversight, as well as an overall lack of transparency (Allin, Davaki \& Mossialos, 2006; Balabanova \& McKee, 2002; Savedoff \& Hussmann, 2006; Thompson \& Witter, 2000; Baji, Rubashkin, Szebik, Stoll \& Vedam, 2017; Cohen, 2012; Tambor, Pavlova, Golinowska, Sowada \& Groot, 2013).

The concept of informal payments encompasses various meanings. Among the various definitions, Lewis (2000, p. 1) considers them as 'payments to individuals or institutions in cash or in kind made outside official payment channels for services that are meant to be covered by the public health care system.' This form of corruption ranges from the ex ante cash payment to the ex-post gift-in-kind made for services that should be free (Allin, Davaki \& Mossialos, 2006; Di Tella \& Savedoff 2001; Lewis, 2006; Vian, 2006). A major challenge is distinguishing the nature of a payment as a gratuity or bribe (Balabanova \& McKee, 2002; Lewis 2002 \& 2007; Ensor, 2004; Allin, Davaki \& Mossialos, 2006; Stepurko, Pavlova, Gryga, Murauskiene \& Groot, 2015).

According to some authors, in order to assess the impact of this phenomenon on the performance of a health care 
system and to identify the most appropriate measures to address them, it is important to distinguish whether informal payments are a form of gratitude or a 'fee-for-service' (Cherecheș 2013; Gaal \& McKee, 2005).

In the first case, the use of informal payments is viewed as a legitimate expression of gratitude and indicates a 'culture of gifts' rooted in the values and traditions of the society where patients live (Balabanova \& McKee, 2002; Baji P., Pavlova, M., Gulacsi, L, \& Groot W., 2013; Cohen, 2012; Szende \& Culyer, 2006). Payments are supposed to be modest, perceived as voluntary, and they are usually given after the treatment; they are therefore a 'benign' phenomenon that does not affect the performance of health systems, especially in terms of equity of access and quality of services.

In the second case, a fee is paid in addition to the official cost-sharing arrangements by patients who hope to receive better or faster treatments (Gaal \& McKee, 2005; Moldovan \& Van de Walle, 2013). This fee is usually given before the treatment and involves a certain degree of coercion (Balabanova \& McKee, 2002; Cherecheș, 2013). This coercion factor is not primarily external but also internal as based on patients' perception that it's impossible to obtain adequate health care without paying this additional sum (Balabanova \& McKee, 2002). Thus, this kind of informal payment is considered as a form of abuse that can undermine official payment systems, distort the priorities of health sector, encourage unprofessional behaviours, and most of all deter access to health services for people with less ability to pay (Allin, Davaki \& Mossialos, 2006; Belli Gotsadze \& Shahriari, 2004; Ensor, 2004; Falkingham 2004; Habibov \& Cheung, 2017; Lewis 2007; Mæstad \& Mwisongo, 2011).

According to many studies, informal payments are associated with inpatient care services, particularly surgery, and are mostly supported by patients in order to have a preferential treatment, such as skipping waiting lists, receiving better or more care, and obtaining drugs (Allin, Davaki \& Mossialos, 2006; Atanasova 2014; Cockcroft, Andersson, Paredes-Solis, Caldwell, Mitchell \& Milne, 2008; Lewis 2007; Tambor, Pavlova, Golinowska, Sowada \& Groot, 2013; Stepurko, Pavlova, Gryga \& Groot, 2010; Meskarpour Amiri, Bahadori, Motaghed \& Ravangard, 2019). Over the past decade, there has been a growing interest in the literature about how corruption can affect health care system performance and what can be done to contrast it (Vian, 2008 \& 2015; Hussmann, 2011, Hutchinson, Balbanova \& McKee, 2019). Since corruption is clandestine, its measurement cannot be $100 \%$ reliable; giving precise measures of it remain difficult and 'perceptions of corruption based on individuals' actual experiences are sometimes the best, and the only, information we have' (Kaufmann, Kraay \& Mastruzzi, 2006).

The most commonly used indicators, based on the perceived levels of corruption of a country, are the Transparency International Corruption Perception Index and the World Bank Governance Indicators. Critics have raised issues with the reliability and adequacy of these indicators (Golden \& Picci, 2005; Knack, 2006; Kurtz \& Schrank, 2007). For example, according to several scholars, the perceptions contained in such indexes (most often experts' assessments) do not necessarily reflect 'actual' corruption as experienced by residents of the particular country in question (Donchev \& Ujhelyi, 2009; Ko \& Samajdar, 2010; Treisman, 2007)

A more targeted measure of corruption for health care systems can be found in the Global Corruption Barometer and, for European countries, in the Eurobarometer survey on corruption in Europe. Both surveys cover people's perception of the extent of corruption in their country and personal experiences of corruption judged by having paid a bribe for services in the last 12 months. The most common critique against such surveys is that data are aggregated at the national level; as a result corruption is assumed to be uniformly spread across each single nation, thus overlooking the fact that for different reasons (socioeconomic, demographic, etc.) specific geographic areas exist within a country wherein corruption is more pervasive (Seligson, 2006; Gingerich, 2013; Charron, Dijkstra \& Lapuente, 2014).

A growing number of studies have documented the adverse effects of corruption on health outcomes, such as child and maternal mortality rates and life expectancy from birth (Azfar, 2005; Gupta, Davoodi \& Tiongson, 2001; Hanf, et al., 2011; Hanf, Nacher, Guihenneuc, Tubert-Bitter, \& Chavance, 2013; Holmberg \& Rothstein, 2011; Rose, 2006). In these studies, however, corruption is based on citizens' perceptions rather than on their actual experiences of bribery to access health services. Only a few authors, measuring actual experiences of petty corruption, have found a positive link between informal payments and standard death rates (Matsushima \& Yamada, 2016), or death rates for women giving birth (Fagan, 2010), or infant mortality (Lewis, 2006; Muldoon, et al., 2011; Matsushima \& Yamada, 2016). Thus, further empirical research is needed for a better understanding of the consequences of bribery on population health status.

At the same time, there is little evidence of the impact of petty corruption on equity of access or on the quality of health services. In regards to equity of access, informal payments increase patients' costs and may thus induce them to forego or delay care (Azfar \& Gurgur, 2008; Belli Gotsadze \& Shahriari, 2004; Falkingham, 2004; 
Lewis, 2000; Rose, 2006; Habibov \& Cheung, 2017; Horodnic, Mazilu \& Oprea, 2018). Their impact on quality is uncertain.

Some scholars argue that the quality of services is better for those who pay informally. This is shown by decreased waiting times, longer length of hospital stays and patients' subjective ratings of quality (Thompson \& Xavier, 1999). It's also true that benefits are restricted mainly to those patients and to the physicians. Doctors, in fact, keep the payment for themselves rather than using it to improve infrastructure or the availability of supplies (Allin, Davaki \& Mossialos, 2006; Belli Gotsadze \& Shahriari, 2004). Other studies contend that payments may have a negative impact on quality, through artificial lowering of service standards, delays of treatment, or unnecessary additional services (Balabanova \& McKee, 2002; McPake et al., 1999; Gaal \& McKee, 2005).

However, no study has jointly considered the consequences of petty corruption on the above-mentioned performance dimensions, nor has any researcher conducted a sub-national level analysis. Finally, most of the studies carried out concern the countries of Central Eastern Europe (Hungary, Bulgaria, Albania, Romania, Poland) and of the former Soviet Union. Few analyse the phenomenon of informal payments in Southern European countries (Horodnic, Mazilu \& Oprea, 2018; Horodnic \& Williams, 2018; Liaropoulos, Siskou, Kaitelidou, Theodorou \& Katostaras, 2008).

The present study intends to contribute to the literature by filling the highlighted gap. To this end, the possible relationships between petty corruption (based on citizens' actual experiences of bribery to access health services, and the different dimensions of RHSs performance for health status, equity of access and quality) will be investigated from a sub-national perspective.

\section{Health Performances and Corruption in Italian NHS}

The Italian NHS was instituted in 1978 in order to provide universal coverage free (or almost free) (Note 1) of charge at the point of use. It is financed by general taxation (Borgonovi, 1988). At the beginning of the 1990s, also because of numerous corruption scandals, the NHS underwent a comprehensive reform process. It was newly designed and structured on a regional basis. Currently, the Italian NHS is institutionally decentralised.

The central level defines the general objectives and fundamental principles of the NHS and finances the essential levels of health services (ELSs) (Note2). The RHSs are responsible for the actual planning and delivery of the ELSs to the entire Italian population through a network of health care organisations and public and private accredited hospitals (Anselmi, 2000; Pavan \& Olla, 2000). In the last two decades, Italian regions have enjoyed increasing and wider autonomy in the way the local NHS functions. Rather than a single NHS, this autonomy has led to 20 different RHSs (Mapelli, 2012).

As a result, Italy has significantly improved the quality of health care in recent years. Indexes for life expectancy at birth, avoidable hospital admissions and survival after severe cardio-circulatory problems are among the best in the EU and OECD countries. The Italian NHS delivers good health services with a lower incidence of health care public expenditure on GDP $(9,1 \%)$ compared to the EU weighted average $(9,9 \%)$. In terms of resources, as compared to the EU average, there are more doctors and fewer nurses per inhabitant in Italy. In addition, equipment levels have increased significantly in recent years (OECD/EU, 2016; OECD, 2015). These reassuring results, however, mask profound differences in the RHSs' comparable performance, with gaps between northern and southern Italian regions (Fattore, 1999; Del Vecchio et al., 2015; Pavolini \& Vicarelli 2012; Reginato, 2016). As a result, many people move between RHSs in search of better-quality care, with northern RHSs being net importers of patients (Toth, 2014).

One of the most negative aspects of Italian health care is corruption. According to the Eurobarometer surveys on corruption, conducted in 2013 and in $2017,97 \%$ and the $89 \%$ of the Italian respondents, respectively, consider corruption a widespread phenomenon and the $44 \%$ (2013) and $45 \%$ (2017) perceive it as prevalent in the health sector. Furthermore, according to the 2013 and 2017 Eurobarometer, 4\% of Italians supported informal payments to access health services (European Commission, 2014, 2017).

Even if the country's system is seriously affected by corruption, the different geographical areas are not involved in the same way. According to some studies (Charron, 2013; Charron, Dijkstra \& Lapuente, 2014; Charron, Dijkstra \& Lapuente, 2015), which analyse and assess the levels of governance in Europe (including corruption among the various indicators), Italy has the highest degree of variation at the regional level.

In Italian NHS the risk of corruption depends on the following factors (Dirindin, 2013; Segato, Del Monte \& Brassiolo, 2014):

- The weakness of the regulatory framework governing the system. Corruption opportunities arise from an inadequate and not fully implemented set of constitutional, state, regional and local rules, which do not clarify 
functions and powers, and use complex or ambiguous languages.

- The asymmetric information between patients and health care providers on the one hand, and between the health system and the drug and medical equipment suppliers on the other. The first information gap can lead to inappropriate health behaviours and improper consumption. The second one can generate opportunities for abuse when spending decisions are driven by the prospect of private gain. Additionally, the infungibility/non fungibility of the health materials is another cause of corruption risk, because it enables public evidence procedures to be bypassed.

- The great political interference in the control and appointment of the top health organisations' managers. As a result, the lack of autonomy from politicians by health authorities may also have repercussions on the attribution of consultancy services, and the procurement and accreditation procedures.

- The ineffectiveness of controls that are made more difficult by the organisational complexity and decentralisation of the health sector. Ex-post controls are often preferred to internal prevention strategies. This involves high costs, as ex-post control mechanisms are a remedial approach that come into play after the system has already paid direct (bribes) and indirect costs (lower quality and higher costs for the public organisation) of corruption.

- The lack of transparency in a sector where, in the name of the privacy protection, access to data is often denied.

According to recent studies conducted by Segato, Pinna, Ceron, Del Monte \& Sardella (2013) and Segato, Del Monte \& Brassiolo (2014), the areas most vulnerable to corruption in the Italian health care sector are: appointments, pharmaceuticals, procurement, private health and medical negligence. In the last area, petty corruption, which is the subject of the present study, is more relevant and generates more social inequalities; it makes access to care dependent on the patient's income. The two main types of negligence, involving abuse of office and private gain at the detriment of the citizens, are mismanagement of waiting lists as well as of intra-moenia (inside the walls) (Note 3). Excessive waiting times are the most critical aspect of Italian health care (Note 4) (Fattore, Mariotti \& Rebba, 2013), and money paid to skip waiting lists represents one of the most common forms of informal payments (Segato, Del Monte, \& Brassiolo, 2013).

\section{Research Objective and Method}

The purpose of the research is to investigate whether and to what extent petty corruption is related to the different dimensions of RHSs performance.

To fulfil the research objective, the research analyses the case of Italian RHSs and uses different sources of information to conduct a multivariate analysis. Data from the European Quality of Government Index (EQI) Survey are used to measure the level of corruption. The EQI survey is the largest multi-country survey mainly concerned with governance of public sector institutions at the sub-national level. Questions are framed around the concepts of quality, impartiality and corruption and ask about citizens' perceptions and experiences of the three main public sector services: education, health care and law enforcement (Charron, Dijkstra \& Lapuente, 2015)

The EQI survey obtains two measures of corruption: a subjective indicator, which expresses a citizen's perception about corruption in their region, or perceived corruption (PC); and an objective measure, which assesses a citizen's 'actual' experience, or experienced corruption (EC). The former indicator is built using a question of the EQI survey that asked citizens to rate on a 0 to 10 scale (where 0 indicates complete disagreement) the extent to which they agreed with the statement: 'Corruption is prevalent in the public health care system in my area.' This measure is used in the research as a proxy for general corruption, which reflects both the grand and the petty one. By contrast, the objective indicator is derived from a question that explicitly asked respondents whether in the last 12 months they or a member of their household paid a bribe in any form to obtain health services. As the subjective indicator may also reflect citizens' perception of grand corruption, this study uses only the objective one.

In order to measure RHSs' performance, three assessment areas are identified: a) population health status (HS); b) access to care (A); and c) quality of care (Q).

The first area evaluates the RHSs population health status through three indicators: life expectancy (Note 5) (LE); standard death rate (Note 6) (STD); and under five mortality rates (Note 7) (UFM).

The second area assesses equity in access to RHSs. The indicators adopted for this focus are: specialist medical examinations skipped due to costs (Note 8) (MtsC); and medical treatment skipped due to waiting times (Note 9) 
(MtsW).

Finally, the quality of Italian RHSs is assessed using the index of Avoidable mortality (Note 10) (AM) as a proxy (Fantini, Lenzi \& Franchino., 2012; Gay, Paris, Devaux \& De Looper, 2011; Gianino, Lenzi, Fantini, Ricciardi \& Damiani, 2017; Kossarova, Holland, Nolte \& McKee, 2009; Nolte \& M. McKee 2004, 2008, 2011; Page, Tobias, Glover, Wright, Hetzel \& Fisher, 2006). Avoidable mortality can be broadly defined as deaths from selected disease groups, which are considered to be either treatable or preventable through health care services (Rutstein et al., 1976). The term includes both amenable and preventable mortality (Tobias \& Jackson, 2001). The former refers to premature death from a set of conditions that should not occur in the presence of timely and effective health care (Nolte \& M. McKee, 2008). The latter includes deaths considered preventable due to primary care or public health policies (Kamarudeen, 2010).

Referencing this literature, the study formulated a research hypothesises that petty corruption has a negative influence on RHS performance. Assuming the null hypothesis that petty corruption has no influence on RHS performance, the following alternative hypotheses are formulated:

H1: Petty corruption is negatively associated with Life expectancy rates (LE).

H2: Petty corruption is positively associated with Under five mortality rates (UFM).

H3: Petty corruption is positively associated with Standard death rates (STD).

H4: Petty corruption is positively associated with Specialist medical examinations skipped due to costs (MtsC).

H5: Petty corruption is positively associated with Specialist medical examinations skipped due to waiting times (MtsW).

H6: Petty corruption is positively associated with Avoidable mortality (AM).

All analysis was conducted at the regional level (NUTS 2). All Italian regions are reported in table 1 together with their geographic location.

The EQI surveys were available for the years 2010, 2013 and 2017. The analysis was conducted using the data from these three years jointly, as single period analyses would be less reliable. Although each year's sample consists of nearly 8,000 observations ( 400 per region), data regional grouping reduces the number of observations to 20 for each year.

As data on RHS performance for the year 2017 was available only for the life expectancy index and in order to overcome this limitation, the other index data for that year were estimated through exponential smoothing performed on the available data.

\section{Data Analysis}

The data sample drawn from the EQI survey included 4,095, 8,510 and 8,400 observations, respectively, for the years 2010, 2103 and 2017. Every record contained information about the region, its EC and its PC. For each year of the survey, data were grouped into regional clusters, so that three groups of 20 regions (table 1) were obtained and the frequency of the value 1 (which indicates a positive answer to the question about having paid a bribe) was considered for EC.

Table 1. Italian regions

\begin{tabular}{lllc}
\hline Region & Area & Region & Area \\
\hline Abruzzo & South & Marche & Centre \\
Basilicata & South & Molise & South \\
Calabria & South & Piemonte & North \\
Campania & South & Puglia & South \\
Emilia-Romagna & North & Sardegna & South \\
Friuli-Venezia Giulia & North & Sicilia & South \\
Lazio & Centre & Toscana & Centre \\
Liguria & North & Trentino Alto Adige & North \\
Lombardia & North & Umbria & Centre \\
Marche & Centre & Valle d'Aosta & North \\
\hline
\end{tabular}

First, the relation between the variables was analysed to understand whether and to what extent RHSs 
performances are associated to EC. For all the variables considered in the analysis, the regional values were computed.

The correlation test (table 2) shows that $\mathrm{EC}$ has a positive correlation with infant mortality rate (UFM) $-\mathrm{r}=$ $0.227 \mathrm{p}=0.081, \mathrm{AM}-\mathrm{r}=0.259, \mathrm{p}=0.046$ and $\mathrm{MtsC}-\mathrm{r}=0.526, \mathrm{p}=0.000-$ while no significant correlations appear with the remaining variables. Because many studies point out a positive association between health performance and wealth, (among others: Marmot, 2002; Pickett and Wilkinson, 2015; Williams, 1990), the correlation test was repeated to control for the latter (wealth) that was expressed in terms of per capita GDP. When considering the regions with a GDP not lower than the national average (table 3), the results show tha EC is positively associated with UFM $-\mathrm{r}=0.451 \mathrm{p}=0.012-$ and $\mathrm{MtsC}-\mathrm{r}=0.568 \mathrm{p}=0.001-$, while it is negatively associated with MtsW $-\mathrm{r}=-0.344 \mathrm{p}=0.063$. In the group of regions with a per capita GDP lower than the national average (table 4), the test shows that the only variable significantly associated to $\mathrm{EC}$ is $\mathrm{Mts} \mathrm{C}-\mathrm{r}$ $=0.459 \mathrm{p}=0.010$.

Table 2. Correlation table: All the regions

\begin{tabular}{|c|c|c|c|c|c|c|c|}
\hline & $\mathrm{EC}$ & LE & UFM & STD & MtsC & MtsW & $\mathrm{AM}$ \\
\hline \multirow[t]{2}{*}{ EC } & 1 & & & & & & \\
\hline & 60 & & & & & & \\
\hline \multirow[t]{3}{*}{ LE } & -0.1203 & 1 & & & & & \\
\hline & 0.36 & & & & & & \\
\hline & 60 & 60 & & & & & \\
\hline \multirow[t]{3}{*}{ UFM } & $0.2274 *$ & $-0.5553^{*}$ & 1 & & & & \\
\hline & 0.0806 & 0 & & & & & \\
\hline & 60 & 60 & 60 & & & & \\
\hline \multirow[t]{3}{*}{ STD } & 0.0261 & $-0.9495^{*}$ & $0.5162 *$ & 1 & & & \\
\hline & 0.8429 & 0 & 0 & & & & \\
\hline & 60 & 60 & 60 & 60 & & & \\
\hline \multirow[t]{3}{*}{$\mathrm{MtsC}$} & $0.5255^{*}$ & $0.2422 *$ & 0.0306 & $-0.3838^{*}$ & 1 & & \\
\hline & 0 & 0.0623 & 0.8167 & 0.0025 & & & \\
\hline & 60 & 60 & 60 & 60 & 60 & & \\
\hline \multirow[t]{3}{*}{ MtsW } & -0.1972 & $-0.3851^{*}$ & $0.2359 *$ & $0.4594 *$ & $-0.7266^{*}$ & 1 & \\
\hline & 0.1309 & 0.0024 & 0.0696 & 0.0002 & 0 & & \\
\hline & 60 & 60 & 60 & 60 & 60 & 60 & \\
\hline \multirow[t]{3}{*}{$\mathrm{AM}$} & $0.2592^{*}$ & $-0.3412 *$ & $0.3375^{*}$ & 0.1754 & $0.3975^{*}$ & -0.2057 & 1 \\
\hline & 0.0455 & 0.0076 & 0.0084 & 0.1801 & 0.0017 & 0.1149 & \\
\hline & 60 & 60 & 60 & 60 & 60 & 60 & 60 \\
\hline
\end{tabular}

Notes. $\mathrm{EC}=$ expected corruption; $\mathrm{PC}=$ perceived corruption; $\mathrm{LE}=$ life expectancy rate; $\mathrm{UFM}=$ under five mortality rate; $\mathrm{STD}=$ standard death rate; $\mathrm{MtsC}=$ specialist medical examinations skipped due to costs; $\mathrm{Mts} \mathrm{W}=$ medical treatment skipped due to waiting times; $\mathrm{AM}=$ avoidable mortality.

Table 3. Correlation table. Regions with a per capita GDP lower than the national average

\begin{tabular}{llllllll}
\hline & EC & LE & UFM & STD & MtsC & MtsW & AM \\
\hline EC & 1 & & & & & & \\
& 30 & & & & & \\
LE & 0.1291 & 1 & & & & \\
& 0.4966 & & & & & \\
& 30 & 30 & & & & \\
UFM & 0.0544 & $-0.6355^{*}$ & 1 & & & \\
& 0.7752 & 0.0002 & & & & \\
& 30 & 30 & 30 & & & \\
STD & 0.0202 & $-0.9378^{*}$ & $0.6441^{*}$ & 1 & & \\
& 0.9157 & 0 & 0.0001 & & & \\
& 30 & 30 & 30 & 30 & & \\
MtsC & $0.4592 *$ & $0.3424^{*}$ & $-0.4094^{*}$ & $-0.4673^{*}$ & 1 & & \\
& 0.0107 & 0.064 & 0.0247 & 0.0092 & & & \\
\hline
\end{tabular}




\begin{tabular}{llllllll}
\hline & EC & LE & UFM & STD & MtsC & MtsW & AM \\
\hline \multirow{4}{*}{ MtsW } & 30 & 30 & 30 & 30 & 30 & & \\
& 0.1598 & -0.302 & $0.4902^{*}$ & $0.3984^{*}$ & $-0.7956^{*}$ & 1 & \\
& 0.399 & 0.1048 & 0.006 & 0.0292 & 0 & & \\
& 30 & 30 & 30 & 30 & 30 & 30 & \\
AM & 0.2138 & $-0.4920^{*}$ & 0.154 & 0.2824 & 0.254 & -0.256 & 1 \\
& 0.2565 & 0.0058 & 0.4165 & 0.1305 & 0.1755 & 0.1722 & \\
& 30 & 30 & 30 & 30 & 30 & 30 & 30 \\
\hline
\end{tabular}

Notes. $\mathrm{EC}=$ expected corruption; $\mathrm{PC}=$ perceived corruption; $\mathrm{LE}=$ life expectancy rate; $\mathrm{UFM}=$ under five mortality rate; $\mathrm{STD}=$ standard death rate; $\mathrm{MtsC}=$ specialist medical examinations skipped due to costs; $\mathrm{Mts} \mathrm{W}=$ medical treatment skipped due to waiting times; $\mathrm{AM}=$ avoidable mortality.

Table 4. Correlation table. Regions with a per capita GDP not lower than the national average

\begin{tabular}{llllllll}
\hline & EC & LE & UFM & STD & MtsC & MtsW & AM \\
\hline EC & 1 & & & & & & \\
& 30 & & & & & & \\
LE & 0.0312 & 1 & & & & & \\
& 0.8699 & & & & & & \\
& 30 & 30 & & & & & \\
UFM & $0.4514^{*}$ & -0.2799 & 1 & & & & \\
& 0.0123 & 0.1342 & & & & & \\
& 30 & 30 & 30 & & & & \\
STD & 0.082 & $-0.9764^{*}$ & 0.2064 & 1 & & & \\
& 0.6665 & 0 & 0.2739 & & & & \\
& 30 & 30 & 30 & 30 & & & \\
MtsC & $0.5679^{*}$ & 0.3057 & $0.3199^{*}$ & $-0.4393^{*}$ & 1 & & \\
& 0.0011 & 0.1004 & 0.0848 & 0.0152 & & & \\
& 30 & 30 & 30 & 30 & 30 & & \\
MtsW & $0.3437^{*}$ & $-0.4078^{*}$ & -0.2089 & $0.4971^{*}$ & $-0.7845^{*}$ & 1 & \\
& 0.0629 & 0.0253 & 0.268 & 0.0052 & 0 & & \\
& 30 & 30 & 30 & 30 & 30 & 30 & \\
AM & 0.2491 & 0.0115 & $0.4616^{*}$ & -0.1278 & $0.5178^{*}$ & -0.2621 & 1 \\
& 0.1844 & 0.9521 & 0.0102 & 0.5009 & 0.0034 & 0.1618 & \\
& 30 & 30 & 30 & 30 & 30 & 30 & 30 \\
\hline
\end{tabular}

Notes. $\mathrm{EC}=$ expected corruption; $\mathrm{PC}=$ perceived corruption; $\mathrm{LE}=$ life expectancy rate; UFM = under five mortality rate; STD = standard death rate; $\mathrm{MtsC}=$ specialist medical examinations skipped due to costs; $\mathrm{MtsW}=$ medical treatment skipped due to waiting times; $\mathrm{AM}=$ avoidable mortality.

Basing on these results, the analysis assessed the influence of corruption on infant mortality (UFM), specialist medical examinations skipped due to costs or waiting times (MtsC and MtsW), and $\mathrm{AM}$. As in the previous correlation analysis, regression tests were first performed to consider all observations and then controlling for per capita GDP. Furthermore, per capita income was also included in the regression models and outliers were excluded using the Bonferroni outliers test.

Given the positive correlation of UFM with EC, this was highlighted in the correlation test, including all of the regions as well as the wealthier ones. However, when the regression analysis was performed without controlling for GDP, the test did not highlight a significant influence of EC on UFM. When the analysis was repeated, controlling for GDP, EC resulted only as a significant predictor of UFM for the group of poorer regions (tables 5, 6 andA7). Furthermore, contrary to the research hypothesis, the influence of the independent variable results was negative. 
Table 5. Infant mortality rate depending on citizens' experienced corruption

\begin{tabular}{llllccc}
\hline UFM & Coef. & Std. Coef. & Std. Err. & t & p-value & Sig. \\
\hline Intercept & 6.594 & 0.000 & 0.464 & 14.21 & 0.000 & $* * *$ \\
Income & 0.000 & -0.733 & 0.000 & -6.98 & 0.392 & $* * *$ \\
EC & -3.019 & -0.187 & 1.696 & -1.78 & 0.080 & $*$ \\
\hline
\end{tabular}

N. of cases: 59

Residual standard error: 0.5193 on 56 degrees of freedom

Multiple R-squared: $\quad 0.4695$ ， Adjusted R-squared: 0.4506

F-statistic: 24.78 on 2 and $56 \mathrm{DF}$, p-value: 0.000

Notes. Infant mortality rate (UFM) is the response variable. Experienced corruption (EC) and Income are the predictors. F-statistic and and its pvalue concern the F-test on the entire set of regression coefficient. Coef is the estimated coefficient, Std. Err. is its standard error, $t$ is the value of the t-test statistic with the associated pvalue. Beta is the standardized regression coefficient.

Table 6. Infant mortality rate depending on citizens' experienced corruption in regions with a per capita GDP not lower than the national average

\begin{tabular}{lllllcc}
\hline UFM & Coef. & Std. Coef. & Std. Err. & t & p-value & Sig. \\
\hline Intercept & 8.776 & 0.000 & 0.697 & 12.59 & 0.000 & $* * *$ \\
Income & 0.000 & -0.859 & 0.000 & -7.14 & 0.000 & $* * *$ \\
EC & -4.071 & -0.273 & 1.795 & -2.27 & 0.032 & $* *$ \\
\hline
\end{tabular}

N. of cases: 29

Residual standard error: 0.4389 on 26 degrees of freedom

Multiple R-squared: 0.6623, Adjusted R-squared: 0.6363

F-statistic: 25.5 on 2 and $26 \mathrm{DF}$, p-value: 0.000

Notes. Infant mortality rate (UFM) is the response variable. Experienced corruption (EC) and Income are the predictors. F-statistic and and its pvalue concern the F-test on the entire set of regression coefficient. Coef is the estimated coefficient, Std. Err. is its standard error, $t$ is the value of the t-test statistic with the associated p-value. Beta is the standardized regression coefficient.

Table 7. Infant mortality rate depending on citizens' experienced corruption in regions with a per capita GDP lower than the national average

\begin{tabular}{lccccc}
\hline UFM & Coef. & Std. Coef. & Std. Err. & t & p-value \\
\hline Intercept & 2.895 & 0.000 & 1.239 & 2.34 & 0.028 \\
Income & 0.000 & 0.026 & 0.000 & 0.13 & 0.900 \\
EC & 3.017 & 2.833 & 2.167 & 1.39 & 0.176 \\
\hline
\end{tabular}

N. of cases: 28

Residual standard error: 0.3449 on 25 degrees of freedom

Multiple R-squared: 0.07613, Adjusted R-squared: 0.002221

F-statistic: 1.03 on 2 and $25 \mathrm{DF}$, p-value: 0.3716

Notes. Infant mortality rate (UFM) is the response variable. Experienced corruption (EC) and Income are the predictors. F-statistic and and its pvalue concern the F-test on the entire set of regression coefficient. Coef is the estimated coefficient, Std. Err. is its standard error, $t$ is the value of the t-test statistic with the associated pvalue. Beta is the standardized regression coefficient.

As for the influence of corruption on MtsC, the regression test, once again, was initially conducted on all the sample observations, and then, controlling for per capita GDP (tables 8, 9 and 10). All tests showed that EC significantly influences the skipping of medical examinations for economic reasons, and the strength of the relation appears stronger when the poorer regions are considered. 
Table 8. Specialist medical examinations skipped due to costs depending on citizens' experienced corruption

\begin{tabular}{lllllll}
\hline MtsC & Coef. & Std. Coef. & Std. Err. & t & p-value & Sig. \\
\hline Intercept & 0.320 & 0.000 & 0.148 & 2.16 & 0.035 & $* *$ \\
Income & 0.000 & 0.186 & 0.000 & 1.51 & 0.137 & \\
EC & 2.025 & 0.489 & 0.511 & 3.96 & 0.000 & $* * *$ \\
\hline
\end{tabular}

N. of cases: 59

Residual standard error: 0.1771 on 56 degrees of freedom

Multiple R-squared: 0.2205 , Adjusted R-squared: 0.1926

F-statistic: 7.919 on 2 and $56 \mathrm{DF}, \quad$ p-value: 0.0009362

Notes. Specialist medical examinations skipped due to costs $(\mathrm{MtsC})$ is the response variable. Experienced corruption (EC) and Income are the predictors. F-statistic and and its pvalue concern the F-test on the entire set of regression coefficient. Coef is the estimated coefficient, Std. Err. is its standard error, $t$ is the value of the $t$-test statistic with the associated pvalue. Beta is the standardized regression coefficient.

Table 9. Specialist medical examinations skipped due to costs depending on citizens' experienced corruption in regions with a per capita GDP not lower than the national average

\begin{tabular}{llllrll}
\hline MtsC & Coef. & Std. Coef. & Std. Err. & t & p-value & Sig. \\
\hline Intercept & -0.536 & 0.000 & 0.644 & -0.83 & 0.412 & \\
Income & 0.000 & 0.289 & 0.000 & 1.66 & 0.109 & \\
EC & 2.184 & 0.467 & 0.815 & 2.68 & 0.013 & $* *$ \\
\hline
\end{tabular}

N. of cases: 29

Residual standard error: 0.1902 on 26 degrees of freedom

Multiple R-squared: $\quad 0.2444$, Adjusted R-squared: 0.1863

F-statistic: 4.205 on 2 and $26 \mathrm{DF}$, p-value: 0.02617

Notes. Specialist medical examinations skipped due to costs (MtsC) is the response variable. Experienced corruption (EC) and Income are the predictors. F-statistic and and its pvalue concern the F-test on the entire set of regression coefficient. Coef is the estimated coefficient, Std. Err. is its standard error, $t$ is the value of the t-test statistic with the associated pvalue. Beta is the standardized regression coefficient.

Table 10. Specialist medical examinations skipped due to costs depending on citizens' experienced corruption in regions with a per capita GDP lower than the national average

\begin{tabular}{|c|c|c|c|c|c|c|}
\hline MtsC & Coef. & Std. Coef. & Std. Err. & $\mathbf{t}$ & p-value & Sig. \\
\hline Intercept & -0.184 & 0.000 & 0.227 & -0.81 & 0.425 & \\
\hline Income & 0.000 & 0.480 & 0.000 & 3.14 & 0.004 & $* * *$ \\
\hline $\mathrm{EC}$ & 2.561 & 0.688 & 0.570 & 4.49 & 0.000 & $* * *$ \\
\hline
\end{tabular}

N. of cases: 29

Residual standard error: 0.1902 on 26 degrees of freedom

Multiple R-squared: 0.2444, Adjusted R-squared: 0.1863

F-statistic: 4.205 on 2 and 26 DF, p-value: 0.02617

Notes. Specialist medical examinations skipped due to costs (MtsC) is the response variable. Experienced corruption (EC) and Income are the predictors. F-statistic and and its pvalue concern the F-test on the entire set of regression coefficient. Coef is the estimated coefficient, Std. Err. is its standard error, $t$ is the value of the $t$-test statistic with the associated pvalue. Beta is the standardized regression coefficient.

Analogously, the influence of petty corruption on treatments skipped due to waiting list was analysed (tables 11, 12 and 13). The test results show that the model explains variations of MtsW, when controlling for GDP, in the group of poorer regions, and when not controlling for GDP. Income per capita also appears as a significant predictor of the MtsW. 
Table 11. Specialist medical examinations skipped due to waiting times depending on citizens' experienced corruption

\begin{tabular}{|c|c|c|c|c|c|c|}
\hline MtsW & Coef. & Std. Coef. & Std. Err. & $\mathbf{t}$ & p-value & Sig. \\
\hline Intercept & 0.356 & 0.000 & 0.062 & 5.71 & 0.000 & $* * *$ \\
\hline Income & 0.000 & -0.469 & 0.000 & -3.80 & 0.000 & $* * *$ \\
\hline $\mathrm{EC}$ & -0.436 & -0.247 & 0.217 & -2.01 & 0.049 & $* *$ \\
\hline
\end{tabular}

N. of cases: 59

Residual standard error: 0.0754 on 56 degrees of freedom

Multiple R-squared: 0.2157, Adjusted R-squared: 0.1877

F-statistic: 7.7 on 2 and 56 DF, p-value: 0.001111

Notes. Specialist medical examinations skipped due to waiting times (MtsW) is the response variable. Experienced corruption (EC) and Income are the predictors. F-statistic and and its pvalue concern the F-test on the entire set of regression coefficient. Coef is the estimated coefficient, Std. Err. is its standard error, $t$ is the value of the $t$-test statistic with the associated pvalue. Beta is the standardized regression coefficient.

Table 12. Specialist medical examinations skipped due to waiting times depending on citizens' experienced corruption in regions with a per capita GDP not lower than the national average

\begin{tabular}{llllccl}
\hline MtsW & Coef. & Std. Coef. & Std. Err. & t & p-value & Sig. \\
\hline Intercept & 0.570 & 0.000 & 0.127 & 4.48 & 0.000 & $* * *$ \\
Income & 0.000 & -0.565 & 0.000 & -3.22 & 0.003 & $* * *$ \\
EC & -0.658 & -0.361 & 0.319 & -2.06 & 0.049 & $* *$ \\
\hline
\end{tabular}

N. of cases: 29

Residual standard error: 0.07814 on 26 degrees of freedom

Multiple R-squared: 0.3038, Adjusted R-squared: 0.2502

F-statistic: 5.672 on 2 and $26 \mathrm{DF}$, p-value: 0.00903

Notes. Specialist medical examinations skipped due to waiting times (MtsW) is the response variable. Experienced corruption (EC) and Income are the predictors. F-statistic and and its pvalue concern the F-test on the entire set of regression coefficient. Coef is the estimated coefficient, Std. Err. is its standard error, $t$ is the value of the $t$-test statistic with the associated pvalue. Beta is the standardized regression coefficient.

Table 13. Specialist medical examinations skipped due to waiting times depending on citizens' experienced corruption in regions with a per capita GDP lower than the national average

\begin{tabular}{lllllll}
\hline MtsW & Coef. & Std. Coef. & Std. Err. & t & p-value & Sig. \\
\hline Intercept & 0.332 & 0.000 & 0.224 & 1.48 & 0.151 & \\
Income & 0.000 & -0.173 & 0.000 & -0.91 & 0.371 \\
EC & -0.468 & -0.317 & 0.281 & -1.67 & 0.107 \\
\hline
\end{tabular}

N. of cases: 29

Residual standard error: 0.06512 on 26 degrees of freedom

Multiple R-squared: 0.106, Adjusted R-squared: 0.03719

F-statistic: 1.541 on 2 and $26 \mathrm{DF}$, p-value: 0.2332

Notes. Specialist medical examinations skipped due to waiting times (MtsW) is the response variable. Experienced corruption (EC) and Income are the predictors. F-statistic and and its pvalue concern the F-test on the entire set of regression coefficient. Coef is the estimated coefficient, Std. Err. is its standard error, $t$ is the value of the t-test statistic with the associated pvalue. Beta is the standardized regression coefficient.

Finally, with regards to the quality aspect, the relation of corruption with AM was analysed (tables 14,15 and 16). The correlation test showed a positive correlation $\mathrm{EC}-\mathrm{r}=0.259, \mathrm{p}=0.045$ - when all the regions are considered. When controlling for GDP, the association between AM and EC did not appear significant for either groups - wealthier or poorer. Based on these results, the possible influence of corruption on AM was investigated. The regression tests showed a significant influence of EC on AM when all regions are considered, although the strength of the relation appears weak and when controlling for GDP in the group of the wealthier regions. However, as before, the strength of the relation appears weak $-\mathrm{R}^{2}=0.1242$. 
Table 14. Index of avoidable mortality depending on citizens' experienced corruption

\begin{tabular}{llllrll}
\hline AM & Coef. & Std. Coef. & Std. Err. & t & p-value & Sig. \\
\hline Intercept & 164.900 & 0.000 & 17.470 & 9.44 & 0.000 & $* * *$ \\
Income & 0.000 & -0.153 & 0.000 & -1.15 & 0.253 & \\
EC & 102.000 & 0.225 & 60.110 & 1.70 & 0.095 & $*$ \\
\hline
\end{tabular}

N. of cases: 59

Residual standard error: 20.89 on 56 degrees of freedom

Multiple R-squared: 0.09364 , Adjusted R-squared: 0.06127

F-statistic: 2.893 on 2 and $56 \mathrm{DF}$, p-value: 0.06374

Notes. Index of Avoidable Mortality (AM) is the response variable. Experienced corruption (EC) and Income are the predictors. F-statistic and and its pvalue concern the F-test on the entire set of regression coefficient. Coef is the estimated coefficient, Std. Err. is its standard error, $t$ is the value of the $t$-test statistic with the associated pvalue. Beta is the standardized regression coefficient.

Table 15. Index of avoidable mortality depending on citizens' experienced corruption in regions with a per capita GDP not lower than the national average

\begin{tabular}{llllrll}
\hline AM & Coef. & Std. Coef. & Std. Err. & t & p-value & Sig. \\
\hline Intercept & 196.86 & 0.000 & 34.269 & 5.74 & 0.000 & $* * *$ \\
Income & -0.003 & -0.272 & 0.002 & -1.40 & 0.173 & \\
EC & 64.648 & 0.147 & 85.842 & 0.75 & 0.458 & \\
\hline
\end{tabular}

N. of cases: 29

Residual standard error: 21.46 on 26 degrees of freedom

Multiple R-squared: $\quad 0.1224$, Adjusted R-squared: 0.05491

F-statistic: 1.813 on 2 and $26 \mathrm{DF}$, p-value: 0.1831

Notes. Index of Avoidable Mortality (AM) is the response variable. Experienced corruption (EC) and Income are the predictors. F-statistic and and its pvalue concern the F-test on the entire set of regression coefficient. Coef is the estimated coefficient, Std. Err. is its standard error, $t$ is the value of the t-test statistic with the associated pvalue. Beta is the standardized regression coefficient.

TableA16: Index of avoidable mortality depending on citizens' experienced corruption in regions with a per capita GDP lower than the national average

\begin{tabular}{lrccccc}
\hline AM & Coef. & Std. Coef. & Std. Err. & t & p-value & Sig. \\
\hline Intercept & 23.320 & 0.000 & 62.480 & 0.37 & 0.712 & \\
Income & 0.006 & 0.348 & 0.003 & 1.93 & 0.065 & $*$ \\
EC & 145.300 & 0.335 & 78.220 & 1.86 & 0.075 & $*$ \\
\hline
\end{tabular}

N. of cases: 29

Residual standard error: 18.34 on 26 degrees of freedom

Multiple R-squared: $\quad 0.1867$, Adjusted R-squared: 0.1242

F-statistic: 2.985 on 2 and $26 \mathrm{DF}, \quad$ p-value: 0.06807

Notes. Index of Avoidable Mortality (AM) is the response variable. Experienced corruption (EC) and Income are the predictors. F-statistic and and its pvalue concern the F-test on the entire set of regression coefficient. Coef is the estimated coefficient, Std. Err. is its standard error, $t$ is the value of the $t$-test statistic with the associated pvalue. Beta is the standardized regression coefficient.

\section{Discussion and Conclusions}

Corruption affects all sectors. But it is an especially critical problem in health care, where, quantitatively, it has been an obscure phenomenon. The difficulty of quantifying corruption in the health sector depends on factors such as: medical confidentiality; the economic and structural dimension of the public service; the number and type of actors involved; the quantity and nature of the services provided; and the difficulties in carrying out systemic checks.

Many studies show that corruption has a corrosive impact on the population's health status, as measured by indicators such as child and maternal mortality rates and life expectancy from birth (Azfar, 2005; Gupta, Davoodi \& Tiongson, 2001; Hanf, Van-Melle, Fraisse, Roger, Carme \& Nacher, 2011; Hanf, Nacher, 
Guihenneuc, Tubert-Bitter \& Chavance, 2013; Lewis 2006; Muldoon et al., 2011; Rose, 2006). There is also a negative effect on the efficiency of public health spending (Rajkumar \& Swaroop, 2008).

More generally, corruption can affect the different performance dimension of a health care system, reducing the resources available for health, lowering the quality and effectiveness of health care services and increasing the cost of provided services. It undermines equity of access to health care by discouraging people who have to pay in order to use health services. Surprisingly, there are only a handful of studies that have systematically analysed the relation between corruption and these different performance dimensions. Some studies have focused on the effect of petty corruption on the equity of access or on the quality of the health service delivery (Azfar and Gurgur, 2008; Belli Gotsadze \& Shahriari, 2004; Falkingham, 2004; Lewis, 2002; Mæstad \& Mwisongo, 2011; Balabanova \& McKee, 2002; McPake, Asiimwe, Mwesigye, Ofumbi, Ortenblad, StreeflandP \&Turinde, 1999; Gaal \& McKee, 2005; Habibov \& Cheung, 2017; Horodnic, Mazilu \& Oprea, 2018). But to date, no study has jointly considered the relation of corruption with the above-mentioned performance dimensions, nor has any study conducted a sub-national level analysis.

The present paper contribute to fill this literature gap, offering a preliminary overview of whether and how petty corruption is related and affects the different performance dimensions of a health system. In order to fulfil the research objective, the Italian NHS case was investigated. The Italian case is important in the European context as Italy has among the widest regional variation in its levels of health care service performance and corruption.

No health system is immune to abuses and frauds, but the specific institutional structures can make particular kinds of corruption more or less attractive. Thus, understanding how a country's health system functions and analysing its vulnerabilities to phenomenon was the first step to carry out. According to previous studies, the Italian NHS is prone to corruption because of (Dirindin, 2013; Del Monte \& Brassiolo, 2014): the weakness of the regulatory framework governing the system; the asymmetric information between patients and health care providers and between providers and the drug and medical equipment suppliers; the great political interference in the control and appointment of top health organisation managers; the ineffectiveness of controls; and the lack of transparency. The health system areas most exposed to the phenomenon are appointments, pharmaceuticals, procurement, private health and medical negligence. With respect to medical negligence, excessive waiting times are the most critical aspect (Fattore, Mariotti, \& Rebba, 2013). They are strictly related to forms of petty corruption that consist in paying bribes to skip ahead of the waiting lists inside public service institutions.

Basing on these considerations, this study assessed whether and to what extent corruption is associated to RHSs's performance. Three dimensions were analysed: health status, access to care and quality of health services.

As for health status, the results showed that EC is positively associated only with UFM. When considering the wealth of regions, EC showed a significant strong correlation with Infant mortality rate only in the wealthier regions. In this respect, the research findings are consistent with its assumption about the importance of analysing corruption at the sub-national level.

However, when the influence of informal payments on the considered indicator was assessed, the test results showed that the rate of infant mortality was negatively influenced by corruption. This result was noted when the test was performed on all regions and on the group of the poorer regions; no significant influence was found when considering the wealthier regions. So, unexpectedly, the study findings are contrary to all the research hypothesis and the extant literature on the subject (Matsushima \& Yamada, 2016; Fagan, 2010; Lewis, 2006; Muldoon, et al. 2011; Matsushima \& Yamada, 2016). A possible explanation for the observed results could lie in the fact that, unlike previous studies, this research has considered one of the 20 richest nations in the world. Further investigation on the subject appears necessary. Specifically, widening the sample to include regions from other western developed countries would be a valuable contribution.

In the matter of access to care, the aspects considered were: specialist medical examinations due to costs and specialist medical examinations skipped due to waiting lists. Once again, the analysis showed mixed results. As for renunciation to specialist medical examinations for economic reasons, the analysis showed that this variable is always strongly and positively associated with the payment of bribes (EC). Based on these findings, the influence of petty corruption on this aspect of access to care was assessed. All the tests performed showed that petty corruption significantly influences specialist medical examinations skipping for economic reasons. This confirms the research hypothesis H4. Moreover, these research findings appear consistent with those studies that show that informal payments can deter access to health services for people with less ability to pay (Allin, Davaki \& Mossialos, 2006; Azfar \& Gurgur, 2008; Belli Gotsadze \& Shahriari, 2004; Falkingham, 2004; Lewis, 2000; Rose, 2006; Habibov \& Cheung, 2017; Horodnic, Mazilu \& Oprea, 2018). 
The relationship between petty corruption and skipping medical examinations due to waiting lists is less straightforward. The findings show that these two variables are significantly correlated only when the wealthier regions are considered. Contrary to the research hypothesis, there is a strong negative correlation, which indicates that renunciations decrease when corruption is more pervasive. The regression analysis highlighted a significant influence of the payment of bribes on the skipping of medical examinations when not controlling for GDP and, when controlling, only in the group of the poorer regions. Based on these findings, the research alternative hypothesis on the positive association of petty corruption with skipping medical examinations because of waiting lists must be rejected in favour of the emerged negative one. These results could be explained considering that where corruption is more pervasive there is a widespread belief that it is possible to skip waiting lists by paying a bribe. Therefore, when waiting lists are too long, citizens use informal payments rather than giving up visits. In fact, according to some studies, informal payments help patients who are in urgent need of treatment to quickly avoid bureaucratic bottlenecks (Onwujekwe et al., 2019; Meskarpour Amiri, Bahadori, Motaghed \& Ravangard, 2019). As no studies exist linking informal payments and waiting lists, further research on the subject appears necessary.

Finally, in terms of quality, there is a positive association with petty corruption when all regions are taken together and when controlling for GDP among wealthier regions. Thus, the research findings only partially confirm the alternative hypothesis of a positive association between bribes and AM. The study does not offer evidence of detrimental effects of petty corruption due to informal payments on the quality of services, which has been scarcely demonstrated in the literature (Balabanova \& McKee, 2002; McPake et al., 2005; Mæstad \& Mwisongo, 2011).

Taken together, the results do not confirm the research hypotheses except in one area: the adverse effect of informal payments on renunciations to specialist medical examinations due to costs. Moreover, the present study shows that when considering corruption regional differences are highly relevant and consistent with the literature recommending corruption analysis at sub-national level (Seligson, 2006). According to some authors, "what seems to be decisive for the well-being of individuals, then, is not the country they live in, but the particular region within that country' (Charron, Dijkstra \& Lapuente, 2015, p. 316).

The study has some limitations that should be addressed in future research. First, the number of variables included in each aspect of the RHS's performance should be increased. This would better capture the observed phenomenon. Also, expanding the number of observations would increase the reliability of the findings. We recommend extending the analysis to regions in other countries, particularly in developed Western nations. The literature on this subject is relatively scarce, and additional research could observe phenomenon within comparable economic contexts. Finally, the analyses use an indicator that considers the actual experience of citizens with informal payments. Therefore, this indicator is affected and limited by the earnestness with which respondents admit to having made them.

\section{References}

Allin, S., Davaki, K., \& Mossialos, E. (2006). Paying for 'free' health care: The conundrum of informal payments in post-communist Europe. In Transparency International (Ed.), Global Corruption Report 2006: Special focus on corruption and health (pp. 62-75). London: Pluto Press.

Anselmi, L. (Ed.). (2000). L'equilibrio economico nelle aziende sanitarie. Milano: Il Sole 24 Ore.

Atanasova, E., Pavlova, M., \& Moutafova, E., Rechel, B., \& Groot, W. (2014). Informal payments for health services: the experience of Bulgaria after 10 years of formal co-payments. European Journal of Public Health, 24(5), 733-739. https://doi.org/10.1093/eurpub/ckt165

Azfar, O. (2005). Corruption and the delivery of health and education services. In B. Spector (Ed.), Fighting corruption in developing countries: strategies and analysis (pp.181-212). Bloomfield, CT: Kumarian Press.

Azfar, O., \& Gurgur, T. (2008). Does corruption affect health outcomes in the Philippines? Economics of Governance, 9(3), 197-244.

Baji P., Pavlova, M., Gulacsi, L, \&Groot W. (2013). Exploring consumers' attitudes towards informal patient payments using the combined method of cluster and multinomial regression analysis - the case of Hungary. BMC Health Services Research, 13, 62. https://doi.org/10.1186/1472-6963-13-62

Baji, P., Rubashkin, N., Szebik, I., Stoll, K., \& Vedam, S. (2017). Informal cash payments for birth in Hungary: Are women paying to secure a known provider, respect, or quality of care? Social Science \& Medicine, 189, 86-95. http://dx.doi.org/10.1016/j.socscimed.2017.07.015 
Balabanova, D., \& McKee, M. (2002). Understanding informal payments for health care: The example of Bulgaria, Health Policy, 62, 243-273.

Belli, P., Gotsadze G., \& Shahriari, H. (2004). Out-of-pocket and informal payments in health sector: evidence from Georgia. Health Policy, 70, 109-123.

Borgonovi, E. (1988). Il Ssn: caratteristiche strutturali e funzionali. In CERGAS (Eds.), Il Servizio Sanitario Nazionale. Milano: Il Sole 24 Ore.

Charron, N. (2013). European Perceptions of Quality of Government: A Survey of 24 Countries. In A. Mungiu-Pippidi (Ed.), Controlling Corruption in Europe. The Anticorruption Report 1. Opladen: Barbara Budrich Publishers.

Charron, N., Dijkstra, L. \& Lapuente V. (2015). Mapping the Regional Divide in Europe: A Measure for Assessing Quality of Government in 206 European Regions. Social Indicators Research, 122, 315-346.

Charron, N., Dijkstra, L. \& Lapuente, V. (2014). Regional governance matters: quality of government within European Union member states. Regional Studies, 48(1), 68-90.

Cherecheș, R., Ungureanu, M., Sandu, P., \& Rus, I. (2013). Defining informal payments in healthcare: a systematic review. Health Policy, 110(23), 105-114.

Cockcroft, A., Andersson, N., Paredes-Solis, S., Caldwell, D, Mitchell, S., \& Milne, D. (2008). An inter-country comparison of unofficial payments: results of a health sector social audit in the Baltic States. BMC Health Services Research, 8-15. https://doi.org/10.1186/1472-6963-8-15.

Cohen, N. (2012). Informal payments for health care-The phenomenon and its context. Health Economics, Policy and Law, 7, 285-308.

Del Vecchio, M., Fenech L., \& Prenestini, A. (2015). Private health care expenditure and quality in Beveridge systems: Cross-regional differences in the Italian NHS'. Health Policy, 119(3), 356-366.

Di Tella, R., \& Savedoff, W. (2001). Diagnosis corruption: fraud in Latin America's public hospitals. Washington DC: Inter-American Development Bank.

Dirindin, N. (Ed.). (2013). Illuminiamo la salute. Per non cadere nella ragnatela dell'illegalità. Roma: Coripe Piemonte, Libera, Avviso Pubblico e Gruppo Abele.

Donchev, D., \& Ujhelyi, G. (2009). What do corruption indices measure? Retrieved Social Science Research Network from http://ssrn.com/paper=1124066

Ensor, T. (2004). Informal payments for health care in transition economies. Social Science \& Medicine, 58, 237-246.

European Commission (2013). Study on Corruption in the Healthcare Sector. Luxembourg: Publications Office of the European Union.

European Commission, (2014). Special Eurobarometer 397 / Wave EB79.1 (2013). Brussels: European Commission.

Fagan, C. (2010). The Anti-Corruption Catalyst: Realizing the MDGs by 2015. Berlin: Transparency International.

Falkingham, J. (2004). Poverty, out-of-pocket payments and access to health care: evidence from Tajikistan. Social Science and Medicine, 58, 247-58.

Fantini, M. P., Lenzi, J., \& Franchino, G. (2012). Amenable mortality as a performance indicator of Italian health-care services. BMC Health Services Researches, 12, 310.

Fattore, G. (1999). Clarifying the scope of Italian NHS coverage. Is it feasible? It is desiderable? Health Policy, $50,123-142$.

Fattore, G., Mariotti, G., \& Rebba, V. (2013). Italy. In Siciliani L., Borowitz M., V. Moran (Eds.), Waiting Time Policies in the Health Sector: What Works? OECD Health Policy Studies, OECD Publishing. https://doi.org/10.1787/9789264179080-en

Gaal, P., \& McKee, M. (2005). Fee-for-service or donation? Hungarian perspectives on informal payments for health care. Social Science and Medicine, 60, 1445-157.

Gay, J.G., Paris, V., Devaux, M., \& De Looper, M. (2011). Mortality amenable to health care. In 31 OECD countries: estimates and methodological issues. OECD Publishing: OECD Health Working Papers-No. 55. 
Gianino, M. M., Lenzi, J., Fantini, M. P., Ricciardi, W., \& Damiani, G. (2017). Declining amenable mortality: a reflection of health care systems? Health Services Research, 17, 735. https://doi.org/10.1186/s12913-017-2708-z

Gingerich, D. W. (2013). Governance indicators and the level of analysis problem: empirical findings from South America. British Journal of Political Science, 43(3), 505-540.

Golden, M. A., \& Picci, L. (2005). Proposal For A New Measure Of Corruption, Illustrated With Italian Data. Economics \& Politics, 17(1), 37-75. https://doi.org/10.1111/j.1468-0343.2005.00146.x

Gupta, S., Davoodi, H. R., \& Tiongson, E. (2001). Corruption and the provision of health care and education services. In Arvind K. Jain (Ed.), The political economy of corruption. London: Routledge.

Habibov, N., \& Cheung, A. (2017). Revisiting informal payments in 29 transitional countries: The scale and socio-economic correlates. Social Science \& $\quad$ Medicine, $178, \quad 28-37$. http://dx.doi.org/10.1016/j.socscimed.2017.02.003

Hanf, M., Nacher, M., Guihenneuc C., Tubert-Bitter P., \& Chavance M. (2013). Global determinants of mortality in under 5s: 10 year worldwide longitudinal study. $B M J, 347$.

Hanf, M., Van-Melle, A., Fraisse, F., Roger A., Carme, B., \& Nacher, M. (2011). Corruption kills: Estimating the global impact of corruption on children deaths. PLoS One, 6(11). https://doi.org/10.1371/journal.pone.0026990

Holmberg, S., \& Rothstein, B. (2011). Dying of corruption. Health Economics, Policy and Law, 6(04), 529-547.

Horodnic, A. V., \& Williams, C. C. (2018). Informal payments by patients for health services: prevalence and determinants. The Service Industries Journal, 38, 11-12, 841-855. https://doi.org/10.1080/02642069.2018.1450870

Horodnic, A. V., Mazilu, S., \& Oprea, L. (2018). Drivers behind widespread informal payments in the Romanian public health care system: From tolerance to corruption to socio-economic and spatial patterns. Int $J$ Health Plann Mgmt., 33, 597-611. https://doi.org/10.1002/hpm.2509

Husmann, K. (2011). Vulnerabilities to corruption in the health sector: perspectives from Latin American sub-systems for the poor, United Nations Development Programme (UNDP).

Hutchinson, E., Balabanova, D., \& McKee, M. (2019). We need to talk about corruption in health systems. International Journal of Health Policy and Management, 8(4), 191-194. https://doi.org/10.15171/ijhpm.2018.123

Kassirer, J. (2006). The corrupting influence of money in medicine. In Transparency International (Ed.), Global Corruption Report 2006: Special focus on corruption and health (pp. 85-91). London, Pluto Press.

Kaufmann, D., Kraay, A., \& Mastruzzi, M. (2006). Measuring corruption: myths and realities. World Bank paper. Washington: DC.

Klomp, J., \& De Haan, J. (2008). Effects of governance on health: a cross-national analysis of 101 countries. Kyklos, 61(4), 599-614.

Knack, S. (2006). Measuring corruption in Eastern Europe and Central Asia: A critique of the cross-country indicators. World Bank Policy Research Working Paper (3968).

Ko, K., \& Samajdar, A. (2010). Evaluation of international corruption indexes: should we believe them or not? The Social Science Journal, 47(3), 508-540.

Kohler, J. C. (2019). I know it when I see it: the challenges of addressing corruption in health systems: Comment on "We need to talk about corruption in health systems." International Journal of Health Policy and Management, 8(9), 563-569. https://doi.org/10.15171/ijhpm.2019.48

Kolstad, I., \& Wiig, A. (2009). Is Transparency the Key to Reducing Corruption in Resource-Rich Countries? World Development, 37(3), 521-532. http://dx.doi.org/10.1016/j.worlddev.2008.07.002

Kossarova, L., Holland, W., Nolte, E., \& McKee, M. (2009). Measuring 'avoidable' mortality: methodological note. Directorate-General "Employment, Social Affairs and Equal Opportunities”. Brussels, Belgium.

Kurtz, M. J., \& Schrank, A. (2007). Growth and Governance: Models, Measures, and Mechanisms. Journal of Politics, 69(2), 538-554. https://doi.org/10.1111/j.1468-2508.2007.00549.x

Lantham S. (2001). Conflict of interest in medical practice. In David M. \& Stark A. (Eds.), Conflict of interest in 
the professions (pp. 279-301). New York: Oxford University Press.

Lewis M. (2002). Informal Health Payments in Central and Eastern Europe and the Former Soviet Union: Issues, Trends and Policy Implications, in Funding Health Care: Options for Europe. Buckingham: Open University Press.

Lewis, M. (2000). Who Is Paying for Health care in Europe and Central Asia? Human Development Sector Unit, Europe and Central Asia Region. Washington D.C.: World Bank.

Lewis, M. (2006). Governance and corruption in public health care systems. Center for Global Development working paper n.78.

Lewis, M. (2007). Informal Payments and the Financing of Health Care in Developing and Transition Countries. Health Affairs, 26 (4), 984-997.

Liaropoulos L. L., Siskou, O., Kaitelidou, D., Theodorou, M., \& Katostaras, T. (2008), Informal payments in public hospitals in Greece. Health Policy, 87(1), 72-81.

Mæstad, O., \& Mwisongo, A. (2011). Informal payments and the quality of health care: Mechanisms revealed by Tanzanian health workers, Health Policy, 99, 107-115.

Mapelli, V. (2012). Il sistema sanitario italiano. Bologna: Il Mulino.

Marmot, M. J. H. (2002). The influence of income on health: views of an epidemiologist. Health Affairs, 21(2), 31-46.

Matsushima, M., \& Yamada, H. (2016). Impacts of Bribery in Healthcare in Vietnam. The Journal of Development Studies, 52(10), 1479-1498. http://dx.doi.org/10.1080/00220388.2015.1121241

McPake, B., Asiimwe, D., Mwesigye, F., Ofumbi, M., Ortenblad, L., Streefland, P., \& Turinde, A. (1999). Informal economic activities of public health workers in Uganda: implications for quality and accessibility of care. Social Science and Medicine, 49, 849-865.

Meridiano, S. (2015). Le coordinate della salute, Rapporto 2015. The European House-Ambrosetti S.p.A. Retrieved http://www.ambrosetti.eu/wp-content/uploads/Meridiano-Sanit\%C3\%A0-2015_Rapporto-Finale_v2.pdf

Meskarpour Amiri, M., Bahadori, M., Motaghed, Z., \& Ravangard, R. (2019). Factors affecting informal patient payments: a systematic literature review. International Journal of Health Governance, 24(2), 117-132. https://doi.org/10.1108/IJHG-01-2019-0006

Moldovan, A., \& Van de Walle, S. (2013). Gifts or bribes? Attitudes on informal payments in Romanian healthcare. Public Integrity, 15(4), 385-402.

Muldoon, K. A., Galway, L. P., Nakajima, M., Kanters, S., Hogg, R., Bendavid, E., \& Mills, E. J. (2011). Health system determinants of infant, child and maternal mortality: A cross-sectional study of UN member countries. Globalization and Health, 7, 42.

Mungiu-Pippidi, A. (2016). For a New Generation of Objective Indicators in Governance and Corruption Studies. European Journal on Criminal Policy and Research, 22(3), 363-367.

Nolte, E., \& McKee, M. (2004). Does Health Care Save Lives? Avoidable Mortality Revisited. London: Nuffield Trust.

Nolte, E., \& McKee, M. (2008). Measuring the Health of Nations: Updating an Earlier Analysis. Health Affairs, $27(1), 58-71$.

Nolte, E., \& McKee, C. M. (2011). Variations in amenable mortality-trends in 16 high income nations. Health Policy, 103, 47-52.

OECD/EU. (2016). Health at a Glance: Europe 2016: State of Health in the EU Cycle. Paris: OECD Publishing. http://dx.doi.org/10.1787/9789264265592-en.

Onwujekwe, O., Agwu, P., Orjiakor, C, McKee, M., Hutchinson, E., Mbachu, C., Odii, A., Ogbozor, P., Obi, U., Ichoku, H., \& Balabanova, D. (2019), Corruption in Anglophone West Africa health systems: a systematic review of its different variants and the factors that sustain them. Health Policy and Planning, 34(7), 529-543, https://doi.org/10.1093/heapol/czz070.

Page, A., Tobias, M., Glover, J., Wright, C., Hetzel, D., \& Fisher, E. (2006). Australian and New Zealand Atlas of Avoidable Mortality. Adelaide: University of Adelaide. 
Pavan, A., \& Olla, G. (2000). Il Management nell'Azienda Sanitaria (2nd ed.). Milano: Giuffrè.

Pavolini, E., \& Vicarelli, G. (2012). Is decentralization good for your health? Transformations in the Italian NHS. Current Sociology, 60(4), 472-488.

Pickett, K. E., \& Wilkinson, R. G. (2015). Income inequality and health: a causal review. Social Science and Medicine, 128, 316-326.

Rajkumar, A. S., \& Swaroop, V. (2008). Public spending and outcomes: Does governance matter? Journal of Development Economics, 86, 96-111.

Reginato, E. (2016). Accountability e controlli in sanità. Santarcangelo di Romagna: Maggioli Editore.

Rose, R. (2006). Corruption is bad for your health: findings from Central and Eastern Europe. In Transparency International (Ed.), Global corruption report 2006: special focus on corruption and health (pp. 39-43). London: Pluto Press.

Rutstein, D. D., Berenberg, W., Chalmers, T. C., Child, C. G., Fishman, A. P., \& Perrin, E. B. (1976). Measuring the quality of medical care. A clinical method. New England Journal of Medicine, 294(11), 582-588.

Savedoff, W., \& Hussmann, K. (2006). Why are health systems prone to corruption? In Transparency International (Ed.), Global Corruption Report 2006 (4-16). London: Pluto Press.

Segato, L., Del Monte, D., \& Brassiolo, M. T. (2014). La corruzione nella sanità italiana. In Libro bianco sulla corruption in sanità. ISPE Sanità.

Segato, L., Pinna, A., Ceron, M., Del Monte, D., \& Sardella, F. (2013). Corruzione e Sprechi in sanità. Milano: Transparency International Italia.

Seligson, M. A. (2006). The measurement and impact of corruption victimization: Survey evidence from Latin America. World Development, 34(2), 381-404.

Stepurko, T., Pavlova, M., Gryga, I., \& Groot, W. (2010). Empirical studies on informal patient payments for health care services: a systematic and critical review of research methods and instruments, BMC Health Services Research, 10, 1-13.

Stepurko, T., Pavlova, M., Gryga, I., Murauskiene, L., \& Groot, W. (2015). Informal payments for health care services: The case of Lithuania, Poland and Ukraine. Journal of Eurasian Studies, 6, 46-58. http://dx.doi.org/10.1016/j.euras.2014.11.002

Szende, A., \& Culyer, A. J. (2006). The inequity of informal payments for health care: The case of Hungary. Health Policy, 75(3), 262-71.

Tambor, M., Pavlova, M., Golinowska, S., Sowada, C., \& Groot, W. (2013). The formal-informal patient payment mix in European countries. Governance, economics, culture or all of these? Health Policy, 113(3), 284-95. https://doi.org/10.1016/j.healthpol.2013.09.011

Thompson, R., \& Witter, S. (2000). Informal payments in transitional economies: Implications for health sector reform. International Journal of Health Planning and Management, 15, 169-187.

Thompson, R., \& Xavier, A. (2002). Unofficial Payments for Acute State Hospital Care In Kazakhstan. A Model of Physician Behaviour with Price Discrimination and Vertical Service Differentiation, Discussion Paper 124/2002. Brussels: LICOS Centre for Transition Economics.

Treisman, D. (2007). What Have We Learned About the Causes of Corruption from Ten Years of Cross-National Empirical Research? Annual Review of Political Science, 10(1), 211-244. https://doi.org/10.1146/annurev.polisci.10.081205.095418

Vian, T. (2006). Corruption in hospital administration. In Transparency International (Ed.), Global Corruption Report 2006: Special focus on corruption and health (pp. 49-53). London: Pluto Press,

Vian, T. (2008). Review of corruption in the health sector: theory, methods and interventions. Health Policy and Planning, 23(2), 83-94.

Vian, T. (2015). How corruption distorts sector performance. In OECD (Ed.), Consequences of Corruption at the Sector Level and Implications for Economic Growth and Development. Paris: OECD Publishing.

Williams, D. R. (1990). Socioeconomic differentials in health: A review and redirection. Social Psychology Quarterly, 53(2), 81-99. 


\section{Notes}

Note 1. Inpatient care and general practitioner services are free of charge, but co-payments are generally required on pharmaceuticals, diagnostic procedures and specialist visits.

Note 2. Essential levels of health services are minimum health services that have to be guaranteed to all citizens; they are defined by and financed from the central government.

Note 3. The term intra-moenia refers to the activity of hospital doctors, who have decided to provide services outside normal working hours using the hospital's facilities and diagnostic equipment. The services are generally the same as those that the doctors provide when they work for the NHS, but the patients have to pay a fee to the doctors. The hospital receives around $25 \%$ of the fee.

Nota 4. The National Plan for Limiting Waiting Lists, established in 2006, sets the maximum waiting times for the provision of services: for specialist appointments 30 days; for diagnostic appointments days 60 .

Nota 5. Source EUROSTAT, 'Life expectancy by age, sex and NUTS 2 region' last update 08-03-2019. https://ec.europa.eu/eurostat/web/products-datasets/product?code=tgs00101.

Nota 6. Source Progetto MEV(i) - Mortalità Evitabile (con intelligenza). www.mortalitaevitabile.it Last update 12-04-2019.

Nota 7. Source ISTAT 2018: ITALIAN DATA FOR UN-SDGs. Sustainable Development Goals of the 2030 Agenda.

Nota 8. Source Istat, Indagine sulle condizioni di vita (UDB IT - SILC) 2010, 2013, 2015.

Nota 9. Source Istat, Indagine sulle condizioni di vita (UDB IT - SILC) 2010, 2013, 2015.

Nota 10. Source Nebo Ricerch ePA: Indicatori regionali MEV(i) 2013, 2016 and 2019. https://www.mortalitaevitabile.it/index.php/area-download/category/11-filedati. The index is calculated as the number of deaths per 100,000 inhabitants over the population aged $0-74$ years

\section{Copyrights}

Copyright for this article is retained by the author(s), with first publication rights granted to the journal.

This is an open-access article distributed under the terms and conditions of the Creative Commons Attribution license (http://creativecommons.org/licenses/by/4.0/). 